\title{
Relações Públicas e Comunicação Organizacional: o lugar do texto e do contexto
}

\author{
Public Relation and Organizational Communication: \\ the place of the text and the context
}

\section{Relaciones Públicas y Comuniceción Organizacional: el lugar del texto y del contexto}

\section{Luiz Carlos lasbeck}

- Doutor e mestre em Comunicação e Semiótica pela Pontifícia Universidade Católica de São Paulo (PUC-SP)

- Graduado em Jornalismo pela Universidade Federal de Juiz de Fora (UFJF)

- Professor e pesquisador do Programa de Pós-Graduação em Comunicação da Universidade Católica de Brasília (UCB)

- Professor titular do Instituto de Educação Superior de Brasília (lesb)

- Coordenador do GT de Estudos do Discurso, da Imagem e da Identidade Organizacionais da Abrapcorp

- Integrante do corpo editorial de diversos periódicos da área da Comunicação

- Autor de A arte dos "slogans": as técnicas de construção das frases de efeitos do texto publicitário e de grande número de capítulos de livros e artigos científicos publicados no País e no exterior

- Tem experiência na área de Comunicação, com ênfase em Semiótica, atuando principalmente nos temas comunicação, semiótica, cultura, comunicação organizacional e publicidade.

- iasbeckk@uol.com.br 
Resumo

Comunicação Organizacional e Relações Públicas são duas áreas do saber e do fazer nas organizações, com lugares próprios, naturezas diferenciadas, fundamentos e finalidades diversas, ainda que seus objetivos sejam comuns. A convivência produtiva com as diferenças que separam seus fundamentos e suas finalidades, desde que assumida, ensina aos profissionais de ambas as áreas e às organizações de modo geral que o exercício da oposição e das desigualdades pode enriquecer sobremaneira o rol de possibilidades de solução para os problemas de comunicação.

PALAVRAS-CHAVE: COMUNICAÇÃO ORGANIZACIONAL • RELAÇÕES PÚBLICAS • CULTURA ORGANIZACIONAL

\section{Abstract}

Organizational Communication and Public Relations are two different areas of knowledge and know-how within organizations, with their own unique places, natures, foundations and diverse purposes, although their objectives are the same. The productive co-existence with the differences that separate their foundations and purposes, provided that they are assumed, shows for professionals of both the areas and for organizations in general that the exercise of opposition and of inequitableness can substantially enrich the list of possibilities for solution of communication problems.

KEYWORDS: ORGANIZATIONAL COMMUNICATION • PUBLIC RELATIONS • ORGANIZATIONAL CULTURE

Resumen

Comunicación Organizacional y Relaciones Publicas son dos áreas del saber y del hacer en las organizaciones, con lugares propios y naturalezas diferenciadas, así como fundamentos y finalidades diversos, a pesar de sus objetivos comunes. La convivencia productiva con las diferencias que separan sus fundamentos y sus finalidades, desde que sea asumida, les enseña a los profesionales de ambas áreas y a las organizaciones, de un modo general, que el ejercicio de la oposición y de las desigualdades puede enriquecer las posibilidades de solución para los problemas de comunicación.

PALABRAS CLAVE: COMUNICACIÓN ORGANIZACIONAL • RELACIONES PUBLICAS • CULTURA ORGANIZACIONAL 
N ão é de hoje que nos debatemos em torno da definição de fronteiras entre essas duas áreas do fazer/saber comunicativo nas organizações. De início veladas, depois suficientemente explícitas, as discussões em torno dos limiares de cada área parecem caminhar para o centro de nossas atenções, ocupações e preocupações.

As motivações para a polêmica são as mais variadas possível. A mais evidente delas, o fato de a Associação Brasileira de Pesquisadores de Comunicação Organizacional e de Relações Públicas (Abrapcorp), em seu próprio nome, privilegiar as duas áreas como distintas da "comunicação nas organizações". Outras motivações para essa polêmica parecem estar na necessidade de se proteger a atuação profissional, temática que repete um outro embate antigo, travado entre comunicadores e profissionais de marketing.

Uma ciência só se afirma como tal quando elege seus paradigmas, constitui seu corpo epistemológico e é reconhecida pela comunidade científica. Essas três condições são cumulativas. Mesmo em tempos de multi-inter-pluridisciplinaridade, uma ciência não pode prescindir de sólidos fundamentos e profundos alicerces para sobreviver ao diálogo da complexidade.

\section{0 lugar do texto}

Iuri Lotman (1988) detém-se no conceito de "texto", considerando-o o elemento fundamental da produção de sentido. O "texto" para ele é a mais perfeita tradução da unidade de sentido; é um conjunto de elementos significativos que possui um sentido próprio, idêntico apenas a si mesmo, o que lhe confere o caráter de imprescindibilidade no concerto dos demais textos da cultura. E, para isso, ele precisa ter expressão e estrutura próprias, além de fronteiras bem definidas.

Perguntamo-nos se é possível determinar quais seriam as expressões, estruturas e fronteiras próprias das duas áreas da comunicação nas organizações, as Relações Públicas e a Comunicação Organizacional. Perguntamo-nos ainda se é válido separar aquilo que parece umbilicalmente unido, em um texto harmônico e coeso. As respostas a tais perguntas requerem um grande esforço e um refinamento muito delicado de especificações intelectuais e técnicas.

A princípio todo texto pode ser separado em suas partes, gerando novos textos, desde que essas partes sejam passíveis de analogia com identidades constituídas e fundamentadas. E é justamente isso que não nos parece ocorrer neste momento no âmbito da comunicação nas organizações.

Relações Públicas e Comunicação Organizacional dividem o mesmo espaço, os mesmos objetos, buscam resultados aproximados, mas utilizam metodologias e aportes teóricos diferentes, quando não dispares. Tem sido comum 
observar que, quando organizações públicas e privadas especializam papéis, criam cargos específicos para os quais não se observam as fronteiras profissionais traçadas pelo costume ou pela tradição.

As Relações Públicas possuem uma epistemologia bem documentada, assentada em teorias e exercícios lógicos de pensadores clássicos e contemporâneos da administração de empresas e da comunicação, organizadas e reformatadas por experts como James E. Grunig, William Ehling, Todd Hunt, Rex Harlow e John White, entre outros.

Inspirados em trabalhos como os de Kotler (1987) e de Lee Thayer (1976), os grandes debates da área nos anos 1990 giraram em torno da circunscrição do trabalho das Relações Públicas às ações administrativas, com vistas a otimizar o discurso e obter imagem positiva das organizações junto aos seus públicos. Kunsch e Simões destacaram-se pelos esforços (isolados) empenhados para organizar a área, premidos, de certa forma, pelos conselhos de classe e demais entidades políticas ligadas à comunicação social e ao marketing.

Entre as razões de ser das Relações Públicas sobrepõem-se as especificações em funções. As atribuições desse profissional, elencadas por Kunsch (2003), estão invariavelmente atreladas às ações de responsabilidade na geração/produção do discurso, na transmissão das informações e no monitoramento contínuo da recepção. Ou seja, os relações-públicas cuidam essencialmente da qualidade do processo da comunicação nas organizações e se distribuem em áreas estratégicas nas quais é possível controlar, coordenar, supervisionar, executar e avaliar, enfim, administrar a comunicação.

São, portanto, gestores, executores e fiscais da Comunicação Organizacional. Os fundamentos teóricos para o desenvolvimento dessas práticas são menos tensos e densos que as práticas elas mesmas, sujeitas a todo tipo de intempéries do ambiente mercadológico, político e social.

\section{Fusões e confusões}

As ações de Marketing não podem prescindir do concurso das Relações Públicas, mas também não devem colidir com elas no que tange à relativa autonomia que tais ações demandam. Enquanto o Marketing está interessado nas vendas, às Relações Públicas cabe cuidar da qualidade da comunicação em todos os âmbitos da organização, inclusive com o consumidor.

Um dos equívocos que levam o Marketing a travar intensos duelos com a Comunicação reside no estranho entendimento de Kotler (2005) de que a "Comunicação é um instrumento do Marketing", submetendo assim a origem ao destino, a causa à consequência, o fato gerador ao fato gerado. Ora, se a comunicação das organizações é um processo tão abrangente quanto e maior do 
que a comunicação de vendas, soa inadequada a inversão dessa lógica. E, se isso acontece nas organizações públicas e privadas, é porque os administradores são mais sensíveis às ações que geram resultados imediatos do que àquelas que se diluem numa vasta gama de agentes da complexidade.

Outra possibilidade de se entender Kotler encontra-se num artigo dele mesmo, publicado em 1987 sob o título "Semiotics of person and nation marketing”. Fica evidente que, para o "pai do marketing”, comunicação não é mais do que divulgação e publicação. Trata-se de uma distorção, fruto de uma visão limitada do que seja comunicação, com consequências bastante graves nas práticas organizacionais.

A discussão sobre os campos de ação do Marketing e das Relações Públicas talvez seja mais urgente e relevante do que aquela que nos propomos aqui, no confronto com a Comunicação Organizacional. Entretanto, as duas discussões não estão desconectadas.

\section{0 contexto do texto}

Por Comunicação Organizacional entendemos o processo de produção, tratamento, transmissão, recepção e retroalimentação de informações que acontecem nos ambientes organizacionais. Não se trata de forma alguma de um processo linear e teleológico, mas de uma intensa e imbricada rede de relacionamento que produze, transforma e consome informação.

Uma das grandes diferenças entre Comunicação Organizacional e Relações Públicas encontra-se na natureza dos seus conceitos: a primeira é antes um pensamento comunicativo, uma abstração necessária à compreensão dos fenômenos que, quando tangíveis e aparentes, podem e devem ser administrados pela segunda; quando aquele pensamento não se atualiza em situações administráveis, só pode ser compreendido e urdido no plano das abstrações e articulações lógicas, no fluxo das ideias.

Metaforicamente poderíamos dizer que as atividades de Comunicação Organizacional estariam mais para as articulações do "arquiteto" do que as funções das Relações Públicas, comparáveis, nessa analogia, às do "engenheiro".

Não nos cabe aqui decidir quem vai construir o edifício, mas são os realizadores que, com certeza, compreenderão melhor as fronteiras que separam e aproximam ambas as atividades. E os que fazem as coisas acontecerem não são, normalmente, vinculados a nenhuma das duas áreas em questão: são os técnicos, os negociadores, os vendedores, os fornecedores, enfim, todo um contingente de agentes de comunicação que não estão preocupados com os destinos da comunicação, mas com o exercício estrito de suas funções. 
O impasse pode ser observado nas ações de planejamento estratégico da Comunicação, função de altíssima relevância no rol das atribuições das Relações Públicas. O planejamento só pode ser realizado se está, desde seu início, orientado por diretrizes estratégicas dadas antes pela alta direção das organizações. Cabe ao planejamento tornar exequíveis tais diretrizes, ainda que necessite questioná-las.

Temos então uma questão de base e de princípios. O pensamento comunicativo da organização não necessita ser administrado, mas ser equacionado, distribuído e dirigido àquelas áreas que podem e devem realizá-lo, atualizá-lo em fatos organizacionais. Essas mesmas áreas técnicas da Comunicação contribuem para o crescimento e a complexidade desse pensamento, dialogando intensamente com suas premissas e colocando-as à prova.

Margarida Kunsch (2003) parece atribuir a Thayer a responsabilidade pela fundação desse ideário de Comunicação Organizacional. A questão sistêmica colocada por Thayer na década de 1970 reverberou nas questões mais amplas e polifacetadas da teoria da complexidade, instaurada nas décadas seguintes e dramaticamente ampliada com o advento das redes informatizadas de comunicação, populares no Brasil desde o final do século XX.

\section{0 lugar de cada um}

À Comunicação Organizacional interessam as questões políticas, éticas, sociológicas, econômicas, antropológicas, filosóficas e psicológicas, entre outras, que afetam a dinâmica organizacional. Interessa estudar e equacionar problemas a partir da abstração e da indução, da análise (dedução) e da demonstração de resultados. Por isso, ela pode fornecer aos profissionais de relações públicas aportes seguros para ações de Comunicação, bem como constituir-se em uma eficiente assessoria ao Marketing, caso esta última área desenvolva sensibilidade para relacionar fenômenos de venda a conceitos e abstrações nem sempre evidentes.

Temos, então, delineadas as linhas mestras que podem carrear para cada um desses dois textos (excluído o Marketing) características explícitas (expressões) e fundamentos implícitos (estruturas) capazes de distingui-los e aproximá-los. Os limites em que cada texto pode comportar-se não são jamais definitivos, pois eles estarão sempre evoluindo, crescendo e/ ou expurgando seus elementos constitutivos, a depender dos desafios que enfrentam e das situações em que o ambiente os situar.

Podemos, ainda, admitir a possibilidade de que a Comunicação Organizacional constitua um texto maior e mais abrangente, capaz de conter o "texto" das Relações Públicas. Seria, nesse caso, seu contexto, seu espaço de envolvimento e, por consequência, um lugar lógico de convivência e de conveniência para os interesses de cada profissional. 
Desse modo, evoluiríamos para um reposicionamento no qual não existe oposição significativa entre as áreas, mas apenas (e isso não é pouco) uma relação de colaboração do tipo continente-conteúdo. Resolver como poderiam conviver profissionalmente especialistas em comunicação e gestores de comunicação não exclui a possibilidade de confrontos francos e decididos. Ao contrário, o enfrentamento é bem-vindo, pois é nessas situações que soluções originais e propostas criativas podem surgir para fazer face às tediosas, redundantes e muitas vezes inoperantes decisões de consenso.

Entendemos, então, que ambas as áreas possuem seus próprios lugares, naturezas diferenciadas, fundamentos e finalidades diversas, ainda que objetivos comuns. A convivência produtiva com as diferenças, desde que assumida, ensinará aos profissionais de ambas as áreas e às organizações que o exercício da oposição e das desigualdades pode enriquecer sobremaneira o rol de possibilidades de solução para as questões de comunicação. E, de resto, pode ser um bom exemplo para as demais áreas que não sabem conviver produtivamente com seus próprios conflitos.

\section{Referências}

IASBECK, Luiz Carlos. A arte dos "slogans": as técnicas de construção das frases de efeitos do texto publicitário. São Paulo: Annablume, 2002.

KOTLER, Philip. Administração de marketing. São Paulo: Pearson, 2005.

Semiotics of person an nation marketing. In: UMIKER-SEBEOK, J. (Org). Marketing and semiotics. Berlin / New York / Amsterdam: Mouton de Gruyter, 1987, p. 03-12.

KUNSCH, Margarida M. Krohling. Planejamento de relações públicas na comunicação integrada. 4. ed. rev., atual. e ampl. São Paulo: Summus Editorial, 2003.

LOTMAN, luri. Estructura del texto artistico. Madrid: Istmo, 1988.

THAYER, Lee. Comunicação: fundamentos e sistemas. São Paulo: Atlas, 1976. 